\title{
GRAMATICALIZAÇÃO DA PREPOSIÇÃO "PARA" NO PORTUGUÊS FALADO NO RIO DE JANEIRO
}

\begin{abstract}
Maurício Rubens de Carvalho Guilherme
Doutorando em Estudos Linguísticos pela Universidade Federal de Minas Gerais (UFMG) mauricio.rubens@gmail.com
\end{abstract}

\section{RESUMO}

O presente artigo tem como objetivo argumentar em favor de que a preposição "para" esteja passando por um processo de gramaticalização. Para tanto, baseia-se nos princípios estabelecidos por Meillet (1912), Kurylowicz (1965), Givón (1979), Lehmman (1982) e Heine (1993), os quais defendem que nesse processo estão presentes fenômenos como erosão fonética, coalescência, abstração e generalização, fenômenos que podem ser observados na preposição em análise. Com a finalidade de exemplificar e ratificar o argumento de que essa preposição esteja passando por um processo de mudança, foi feito um levantamento das ocorrências da citada preposição, em suas formas plena e reduzida, no corpus do projeto Norma Linguística Urbana Culta do Rio de Janeiro (NURC/RJ). O que se pôde concluir a partir dessa análise foi que a redução da preposição mencionada é maior quando esta apresenta conteúdo semântico mais abstrato, ratificando a argumentação de que esteja ocorrendo um processo de gramaticalização.

Palavras-chave: gramaticalização, preposições, variação linguística, erosão.

\section{ABSTRACT}

The present paper argues that the preposition "para" ("to"; "for") is undergoing a process of grammaticalization. Thus, it is based on the principles established by Meillet (1912), Kurylowicz (1965), Givón (1979), Lehmman (1982) and Heine (1993), who defend that in this process are present phenomena such as phonetic erosion, coalescence, abstraction and generalization, which can be observed in the preposition under analysis. In order to exemplify and ratify the argument that this preposition is undergoing a process of change, we made a survey of the occurrences of the aforementioned preposition (both in its full and reduced forms) in the corpus of the project Norma Linguística Urbana Culta do Rio de Janeiro (NURC/RJ). We could conclude from this analysis that the reduction of the mentioned preposition is greater when it presents more abstract semantic content, ratifying the argument that a grammaticalization process is taking place.

Keywords:

gramaticalization, prepositions, linguistic variation, erosion.

\section{Introdução}


O presente artigo tem como objetivo demonstrar que a redução da preposição "para" é resultado de um processo de gramaticalização, que, segundo Kurylowicz (1965), é o processo por meio do qual não somente itens lexicais se tornam gramaticais, mas também itens gramaticais se tornam mais gramaticais, dentro de um continuum.

Este trabalho é resultado da hipótese de que as formas reduzidas dessa preposição têm apresentado uma frequência bem maior do que a sua forma plena. Além disso, em uma observação mais atenta, pode-se perceber que, além de haver mais de uma forma reduzida dessa preposição, o que se tem, na verdade, é uma escala de redução fonética resultante do processo de gramaticalização, como se pode ver:

para $>$ pra $>$ pr $>p$

Para exemplificar cada uma dessas formas, segue uma sequência de frases ditas por falantes em momentos de espontaneidade e captadas para registro neste trabalho.

(1) eu de vez em quando... vou para a casa de uns colegas meus.

(2) falou em... me chamar pra acampar eu vou tranquilo...

(3) leva um material diferente daquele que vai levar pro campo...

(4) a. Todo dia eu tenho que falar $\boldsymbol{p}^{\prime}$ o [pu] meu irmão me esperar depois da aula.

b. Eu deixei a compra $\boldsymbol{p}^{\prime}$ cê guardar pra mim.

Como se pode ver, há pelo menos três formas reduzidas da preposição "para", e todas são usadas sincronicamente. Isso se dá pelo fato de tratar-se de um fenômeno ainda em curso na língua, no qual o que se tem até então é um processo de variação. 
Temos que admitir, entretanto, que o último estágio dessa sequência, exemplos (4a) e (4b), é ainda muito estigmatizado e presente apenas em algumas interações muito específicas, nas quais o nível de monitoramento é muito baixo, ou, ainda, em alguns dialetos mais restritos. Sendo assim, tal forma torna-se difícil de ser captada por meio de entrevistas sociolinguísticas com alguns grupos de falantes, em que, por mais naturalmente que se tente proceder, a própria presença do entrevistador, com uso de aparelhos de gravação, questionários etc., inibe a realização de formas muito inovadoras.

Todavia, mesmo entre falantes cultos da língua, pode-se perceber grande variação. Para exemplificar isso, serão apresentados ao longo do texto dados retirados de entrevistas feitas pelo projeto "Norma Urbana Culta do Rio de Janeiro" (NURC/RJ), os quais representam diálogos entre dois informantes (D2) de três faixas etárias diferentes - de 25 a 35 anos (Faixa etária 1), de 36 a 55 anos (Faixa etária 2) e acima de 56 anos (Faixa etária 3) -, todos com curso superior, que são os falantes analisados pelo projeto. Abaixo estão alguns exemplos retirados do corpus.

(5) o tempo está feio... isto eu lhe garanto... né... agora... saindo do tempo pras viagens você disse que esteve em Recife (Faixa etária 1)

(6) mas de qualquer forma no máximo um mês eu já estou começando a ficar nervosa... pra vir pro movimento (Faixa etária 2)

(7) dificultar o mais possível... que os particulares tragam os seus carros pra cidade... (Faixa etária 3)

Como se pode ver, no exemplo (5), a preposição "para" foi reduzida para apenas "pr", uma vez que foi contraída com o artigo feminino plural "as". Já no exemplo (6), a preposição "para" foi reduzida para "pra”, já que diante do verbo vir não se pode inferir a presença de um artigo, e para "pr" diante do artigo masculino singular "o". No exemplo 
(7), por sua vez, a redução da preposição "para" também produziu a forma "pr", já que o fonema [a] que segue o encontro consonantal "pr" é o artigo do substantivo feminino "cidade".

Diante disso, o presente trabalho busca demonstrar como se dá essa distribuição das formas reduzidas em cada faixa etária, dentro do corpus estudado, além de tentar explicar o fenômeno em questão.

\section{Estatuto teórico de gramaticalização da preposição "para"}

O primeiro a usar o termo gramaticalização foi Meillet (1912), em seu trabalho intitulado L'évolution des formes grammaticales. Para o autor, a gramaticalização seria um processo por meio do qual itens lexicais se tornariam, através de um continuum, itens gramaticais. Entendam-se itens lexicais como palavras que possuem referencialidade no mundo, ou seja, aquelas que apontam para a realidade biossocial; itens gramaticais, por sua vez, são aquelas palavras que não possuem referencialidade, mas que têm uma função estrutural dentro do discurso, conectando outras palavras e funcionando como organizadores do texto.

Embora tenha sido Meillet (1912) o cunhador do termo, sabe-se que a ideia de que itens lexicais podem se transformar em itens gramaticais não surgiu com ele. No século $X$, um chinês chamado Zhou Bo-qi já fazia referência à mudança de símbolos cheios para símbolos vazios. Além dele, no século XVIII, filósofos franceses, como Condilac ${ }^{1} \mathrm{e}$ Rousseau ${ }^{2}$, defendiam que tanto palavras abstratas quanto noções gramaticais teriam se originado de palavras concretas. É de Condilac (1746) a ideia de que flexões verbais teriam sua origem em palavras independentes mais antigas. 
Entretanto, contribuições posteriores a Meillet (1912) aprimoraram a noção de gramaticalização, como a clássica definição apresentada por Jerzy Kurylowicz (1965:65), o qual afirma que "a gramaticalização consiste no aumento do percurso de um morfema que avança do léxico para a gramática ou de um estado menos gramatical para um estado mais gramatical".

Esta afirmação de Kurylowicz é fundamental para este trabalho, uma vez que nele se afirma que a preposição "para”, ou seja, um item já gramatical, está passando por um processo de gramaticalização. Um dos argumentos para essa afirmação está na alegação de Heine (1993), o qual diz que um dos efeitos desse processo é a erosão, a qual causa, além da perda de substância fonética, diminuição da independência fonológica, fazendo com que o item, no caso a preposição "para", torne-se uma espécie de clítico e tenha que se apoiar fonologicamente em itens posteriores.

A aceitação desse argumento justificaria o fato de esse item estar sofrendo primeiramente a perda da vogal tônica e não da vogal átona, como é mais comum ocorrer, defendendo-se que no momento em que a preposição "para" se torna "pra", entre outras variantes, ela está perdendo seu status de palavra fonologicamente livre, tornando-se um clítico da palavra posterior. Tal fato evidencia o processo de gramaticalização, tendo em vista que uma preposição, embora já seja de natureza gramatical, possui um status de elemento fonologicamente livre, enquanto um clítico possui uma natureza fonológica dependente de outro item lexical, o que o torna um item mais gramatical do que uma preposição típica.

Para essa discussão, tomam-se ainda como referência os estudos de Givón (1979) e Lehmman (1982), os quais defendem que o processo de gramaticalização ocorre de 
forma gradativa e diacrônica, segundo uma ordem que é descrita na sequência abaixo, proposta por Givón (1979):

Discurso $>$ Sintaxe $>$ Morfologia $>$ Morfofonêmica $>$ Zero

Segundo Lehmann, essa escala é resultado de duas afirmações de Givón: "a morfologia de hoje é a sintaxe de ontem" (GIVON, 1971, p. 413) e "a sintaxe de hoje é o discurso pragmático de ontem" (GIVON, 1979, p. 208-209).

Para a presente análise, a preposição "para" estaria no estágio em que deixa de ser um elemento sintático, tornando-se parte da morfologia, uma vez que, no momento em que perde seu status de morfema livre, tornando-se um clítico, perde mobilidade e torna-se cada vez mais presa, tendendo a se transformar em um morfema no futuro.

Além disso, segundo Heine (1993), durante esse processo, os itens podem perder substância fonética, o que ele chama de erosão, podendo apresentar os seguintes efeitos:
a) Itens polissilábicos tornarem-se monossilábicos;
b) Sons complexos, como encontros consonantais, serem substituídos por sons mais simples;

c) Fonemas longos/geminados serem substituídos por fonemas curtos/nãogeminados;

d) Fonemas segmentais darem lugar a não-segmentais (suprassegmentais), ou serem perdidos;

e) Vogais nasais tenderem a ser substituídas pelas orais correspondentes;

f) A marcação do acento tônico tender a ser perdida. 
Para o fenômeno em questão, podem-se perceber alguns dos efeitos mencionados por Heine (1993). Primeiramente, a preposição "para", que é um item de duas sílabas, ao ser pronunciada como "pra", torna-se uma palavra monossilábica, conforme o efeito (a).

Em segundo lugar, ainda se pode alegar que esteja ocorrendo o efeito presente em (b) mencionado por Heine (1993), uma vez que dados como o exemplificado em (4b) e repetido abaixo são frequentes na fala espontânea de pessoas em várias partes do país.

(8) Eu deixei a compra $\boldsymbol{p}^{\prime}$ cê guardar pra mim.

Exemplos como o citado acima revelam que formas complexas tendem a se tornar mais simples, como é o caso do encontro consonantal "pr", que se torna apenas " $p$ ".

Para finalizar, esse fenômeno de redução difere da maioria dos casos de redução fonológica, uma vez que normalmente a redução ocorre primeiramente com a perda de uma vogal átona, enquanto neste caso ocorre a perda da vogal tônica, ou seja, o primeiro [a] da palavra. Assim, o efeito presente em (f) também ocorreria aqui, já que ocorre a perda do acento tônico.

Essa perda do acento tônico gera consequências de natureza prosódica, pois o item que possuía acentuação própria tenderá agora a se apoiar fonologicamente em outro item, tornando-se assim um clítico, o que é mais um argumento de que esteja ocorrendo a gramaticalização dessa preposição.

\section{A redução da preposição "para" na fala de indivíduos cultos}


É comum se pensar que a variação linguística é uma realidade que só ocorre entre falantes de dialetos menos prestigiados, os quais, por desconhecimento da normapadrão, cometem "erros que corrompem a língua". Entretanto, graças aos estudos de Willian Labov, entre outros autores, desde a década de 1960, tem-se entendido que as variações são processos previsíveis e recorrentes em todas as línguas e em todas as épocas, sendo inerentes à própria língua como sistema.

Isso pode ser visto, inclusive, quando se analisa a fala de pessoas escolarizadas e se percebe que as variações estão presentes em todas as camadas da sociedade, revelando mais uma vez que não se trata de um "erro" decorrente da falta de educação formal ou de condições socioeconômicas, mas, sim, de um processo linguístico natural que permeia toda a sociedade.

Tendo isso em vista, foram selecionados para esta pesquisa dados do projeto Norma Urbana Culta do Rio de Janeiro (NURC/RJ), os quais refletem a fala de pessoas escolarizadas, tendo em vista seu objetivo de captar a fala das pessoas mais cultas da sociedade. Esses dados foram coletados na década de 1970 e 1990 e já demonstram um nível avançado de superação da forma plena pelas formas reduzidas da preposição "para".

Os dados selecionados foram do tipo Diálogos entre dois informantes (D2) e se compõem de seis inquéritos, realizados com informantes de três faixas etárias diferentes. Os inquéritos D2/158 e D2/147 se referem à primeira faixa etária, de 25 a 35 anos, e os informantes têm formação universitária nas áreas de Engenharia mecânica, Filosofia e Bioquímica. Os inquéritos D2/256 e D2/255 são de falantes da segunda faixa etária, de 36 a 55 anos, com formação universitária nas áreas de Belas artes, Geografia, Desenho e 
Arquitetura. Por fim, os inquéritos D2/296 e D2/374 apresentam falantes da terceira faixa etária, acima de 56 anos, com formação superior em Medicina, Odontologia, Filosofia e Pedagogia.

A tabela a seguir representa o uso das formas da preposição "para" em cada uma das faixas etárias. Na primeira coluna, estão as formas encontradas no corpus analisado. Na primeira linha, está a forma plena "para"; na segunda linha, a forma reduzida "pra", sem a possibilidade de que esteja contraído com um artigo feminino, já que a palavra posterior não o admitiria, como em: "ah... conta pra mim...". Já na terceira linha, tem-se a forma "pr" seguida do artigo feminino (a/as), como em "então pedia pra gente escrever o jogo..."; e, por fim, a quarta linha contém as ocorrências da forma "pr" seguida do artigo masculino (o/os), como em "...viagens que fizeram pro Brasil...".

Tabela 1: Ocorrências da preposição "para" nas formas plena e reduzida.

\begin{tabular}{lccc}
\hline & $\begin{array}{l}\text { Faixa etária } \\
\mathbf{1}(\mathbf{\%})\end{array}$ & $\begin{array}{l}\text { Faixa etária } \\
\mathbf{2}(\mathbf{\%})\end{array}$ & $\begin{array}{l}\text { Faixa etária } \\
\mathbf{3}(\mathbf{\%})\end{array}$ \\
\hline para & 6,1 & 20,8 & 23,7 \\
pra & 74,7 & 61,5 & 55,8 \\
pr+a(s) & 11,1 & 8,9 & 8,9 \\
pr+o(s) & 8,1 & 8,8 & 11,6 \\
Total & 100 & 100 & 100 \\
& & & \\
\hline
\end{tabular}

Fonte: NURC/RJ

Na tabela, pode-se perceber que as formas reduzidas são muito mais utilizadas do que a forma plena da preposição "para", somando 93,9\% na Faixa etária 1; 79,2\% na faixa etária 2 e 76,3\% na faixa etária 3. Esses dados são muito significativos, uma vez que revelam uma preferência muito acentuada de utilização das formas reduzidas em detrimento da forma plena da preposição. Além disso, indicam uma crescente tendência 
ao uso das formas reduzidas, já que as gerações mais jovens (faixa etária 1) estão mostrando uma enorme predileção pelas formas reduzidas em comparação a outras faixas etárias.

A argumentação de que esteja ocorrendo um incremento do processo de gramaticalização desse item fica muito evidente a partir da apresentação dos dados. Primeiramente, pelo fato de que, com a queda da vogal tônica da palavra "para > pra", surge a necessidade de este item, que antes era um morfema dependente, apoiar-se fonologicamente na palavra posterior, tornando-se um clítico. Isso fica mais perceptível quando o item se contrai com o artigo subsequente ou com outras palavras, como no exemplo abaixo, retirado de uma entrevista realizada com falantes da zona rural de Piranga (MG):

(1) ...eu nunca mais vô trabaia procê nem vô trabaia procê porque cê tem escada rolante...

Isso nos mostra claramente o novo status clítico adquirido pelo item, fazendo com que um elemento que já possui função gramatical se torne ainda mais gramaticalizado ao deixar de compor uma construção sintática para compor uma construção morfológica, assim como afirmado por Givon (1871, p. 413): “a morfologia de hoje é a sintaxe de ontem".

\section{A redução da preposição de acordo com o tipo de complemento}

Além de se perceber a clara preferência dos falantes pelas formas reduzidas da preposição "para", ao se fazer a análise dos dados, pôde-se perceber que houve uma 
diferença na taxa de redução do item em análise de acordo com o tipo de elemento que o seguia. Assim, segue a tabela que apresenta a redução da preposição de acordo com o tipo de elemento subsequente.

Tabela 2: Ocorrências da preposição "para" conforme elemento subsequente.

\begin{tabular}{lcc}
\hline Tipo de complemento & $\begin{array}{c}\text { Forma } \\
\text { plena (\%) }\end{array}$ & $\begin{array}{r}\text { Forma } \\
\text { reduzida (\%) }\end{array}$ \\
\hline Verbo & 17,7 & 82,3 \\
\hline Artigo feminino & 16,8 & 83,2 \\
\hline Artigo masculino & 19,9 & 80,1 \\
\hline Pronome pessoal & 12,0 & 88,0 \\
\hline Numeral & 8,3 & 91,7 \\
\hline Locativo & 3,2 & 86,8 \\
\hline Substantivo masculino & 14,6 & 85,4 \\
\hline Nome de cidade (s/artigo) & 0,0 & 100,0 \\
\hline Palavra "casa" (própria) & 0,0 & 100,0 \\
\hline Demais pronomes (s/artigo) & 30,2 & 69,8 \\
\hline Advérbio & 44,4 & 55,6 \\
\hline
\end{tabular}

Como se pode ver na tabela 2 , há um predomínio no uso das formas reduzidas independentemente do tipo de complemento, chegando a ser categórica sua utilização diante de topônimos referentes a nomes de cidade, sem o uso de artigo, e da palavra "casa", quando se refere à própria casa. Tais dados revelam uma tendência à generalização do uso da forma reduzida em ambientes linguísticos mais variados, o que corrobora a afirmação de que esteja ocorrendo um processo de gramaticalização, tendo em vista que, segundo Bybee e Pagliuca (1985, p. 63), em processos de gramaticalização, ocorre uma generalização, isto é, morfemas apresentam uma distribuição mais geral, podendo ser usados em mais contextos, que é o que se pode observar nos dados acima. 


\section{A redução da preposição de acordo com o conteúdo semântico}

Outro aspecto que foi observado durante a análise é que, conforme o conteúdo semântico da preposição se alterava, revelavam-se diferenças nas taxas de redução. Basicamente, a preposição em análise apresentou cinco diferentes conteúdos semânticos: finalidade, espaço, tempo, opinião e destinação.

Além disso, uma quantidade relevante de ocorrências da preposição não possuía nenhuma carga semântica, sendo usada apenas como um elemento estrutural requerido pela regência da palavra anterior. Seguem exemplos de cada tipo de uso, conforme os conteúdos semânticos em que foram usados.

(1) "ele corre as mesas pra bater papo depois na hora de dançar ele cai em cima das mulheres..." (finalidade)

(2) "nesse feriado eu fui para a fazenda deles... né e um dia eu fui pra cidade..." (espaço)

(3) "dali pra frente... eles começaram a pensar mais em limpar os esgotos..." (tempo)

(4) "aquilo pra mim era uma coisa assombrosa..." (opinião)

(5) "porque não vai levar comida pra um batalhão... né?..." (destinação)

Além dos exemplos acima, como mencionado anteriormente, houve casos em que a preposição só foi usada para atender à demanda regencial da palavra anterior, como se pode ver no exemplo a seguir: 
(6) "você pode sair vestida de palhaço de lá... que ninguém vai olhar pra você..."

Como se pode ver no exemplo (15), a preposição não possui nenhum dos conteúdos semânticos listados acima, e, sim, cumpre apenas uma função estrutural. A tabela a seguir apresenta os significados em que a preposição "para" e suas variantes foram utilizadas no corpus analisado.

Tabela 3: Ocorrências da preposição "para" conforme conteúdo semântico

\begin{tabular}{lcc}
\hline & $\begin{array}{c}\text { Forma } \\
\text { Plena (\%) }\end{array}$ & $\begin{array}{r}\text { Forma } \\
\text { Reduzida (\%) }\end{array}$ \\
\hline Finalidade & 21,5 & 78,5 \\
Espaço & 14,4 & 85,6 \\
Destinação & 35,9 & 64,1 \\
Tempo & 7,1 & 92,9 \\
Opinião & 9,7 & 90,3 \\
Sem conteúdo semântico & 9,4 & 90,6 \\
\hline
\end{tabular}

Fonte: NURC/RJ

Como se pode ver na tabela 3 , os usos que apresentam menor grau de concretude, como tempo, opinião e aqueles que não possuem carga semântica, exibem uma redução mais forte do que aqueles em que a carga semântica é associada a elementos mais referenciais no mundo.

Segundo Barreto (2012, p. 409), "do ponto de vista semântico, os processos de gramaticalização, na sua maioria, envolvem uma metaforização, isto é, a passagem de um conteúdo concreto para outro mais abstrato". A autora ainda cita a hierarquia proposta por Heine, Claudi e Hünnemeyer (1991, p. 157), que afirmam que, no processo de 
gramaticalização, ocorre um movimento em direção a uma maior abstração, que é representada pelos elementos mais à direita do continuum a seguir:

pessoa $>$ objeto $>$ atividade $>$ espaço $>$ tempo $>$ qualidade

Para os autores, um determinado item, durante o processo de gramaticalização, tende a desenvolver significados em domínios mais à direita na sequência mostrada. Por exemplo, a preposição "para" muitas vezes é usada no domínio temporal por um processo de abstração do domínio espacial. É o que se pode ver no exemplo (12), em que a expressão "dali pra frente" refere-se a algo que passou a acontecer a partir daquele momento, no entanto usa expressões provenientes do domínio espacial, como "ali" e "frente", para se referir a noções temporais.

A partir dessas observações, pode-se inferir mais uma vez que a redução da preposição "para" é resultado de um processo de gramaticalização, uma vez que, quando essa preposição é utilizada com conteúdos semânticos mais abstratos, como tempo, opinião, ou ainda sem um conteúdo semântico claro, as taxas de redução são bem maiores, superando os $90 \%$.

\section{Considerações finais}

O presente artigo tentou demonstrar, assim como afirma Kurylowicz (1965), que itens que já são gramaticais, como preposições, podem se tornar ainda mais gramaticais, como clíticos, por exemplo. Além disso, como se pôde perceber a partir dos dados analisados, as novas gerações têm utilizado cada vez mais as formas reduzidas da 
preposição "para", o que nos leva a concluir que se trata de um fenômeno que tende a aumentar com o passar do tempo, resultando inclusive no desaparecimento da forma plena. Outra informação importante revelada por essa análise é que a taxa de utilização das formas reduzidas é ainda maior quando a mencionada preposição apresenta conteúdos semânticos mais abstratos, que é também uma das características do processo de gramaticalização.

Processos de mudança linguística são inerentes a todas as línguas e não devem ser considerados como corrupção ou deterioração de uma língua. Hoje já está claro que as mudanças não ocorrem de maneira fortuita e desordenada, mas apresentam regularidade e direção.

Entre os estudos de mudança linguística, estão aqueles que tratam do processo de gramaticalização, que vêm sendo desenvolvidos cada vez mais frequentemente, uma vez que se tem percebido ser um fenômeno muito recorrente nas mais variadas línguas. É verdade, entretanto, que não se trata de um fenômeno totalmente esclarecido, em que pese a sua complexidade e abrangência. Todavia, vários estudos têm demonstrado sua pertinência e plausibilidade.

Assim, coube a esse trabalho, modestamente, fornecer mais dados que reforcem essa teoria a fim de que se esclareçam constantemente as circunstâncias em que tal fenômeno ocorre. Os itens chamados tradicionalmente de preposições são elementos sobre os quais o fenômeno da gramaticalização parece incidir muito frequentemente, talvez pela posição intermediária, entre itens lexicais e gramaticais, que esses vocábulos ocupam. 
Dessa forma, há ainda muito que se pesquisar a respeito dos efeitos da gramaticalização sobre as preposições, a fim de que possamos definir melhor os limites dessa classe tão variada e heterogênea.

\section{Referências}

BARRETO, T. Lexicalização e gramaticalização: processos independentes ou complementares?. In: LOBO, T. et al. (orgs.). Rosae: linguística histórica, história das línguas e outras histórias [online]. Salvador: EDUFBA, 2012. p. 407-416.

BYBEE, J.; PAGLIUCCA, W. Cross-linguistic comparison and the development of grammatical meaning. In: FISIAK, J. (org.). Historical semantics: historical word-formation. Berlin/New York: Mouton de Gruyter, 1985.

CONDILLAC, E. B. Essai sur l'origine des connaissances humaines. Paris: Librairie Armand Colin, 1746.

GIVÓN, T. Historical syntax and synchronic morphology: an archaeologist's field trip. Chicago Linguistic Society, n. 7, p. 394-415, 1971.

GIVÓN, T. On understanding grammar. New York: Academic Press, 1979.

HEINE, B. Auxiliaries: cognitive forces and gramaticalization. Oxford; New York: Oxford University Press, 1993.

HEINE, B.; CLAUDI, V.; HÜNNEMEYER, F. Grammaticalization: a conceptual framework. Chicago; London: The University of Chicago Press, 1991.

KURYLOWICZ, J. The evolution of grammatical categories. In: Esquisses Linguistiques II. München: Fink, 1965. p. 38-54.

LEHMANN, C. Thoughts on grammaticalization: a programmatic sketch. Vol. 1. Köln: Institut für Sprachwissenschaft der Universität, 1982. (Arbeiten des Kölner Universalien Projekts, 48).

MEILLET, A. L'évolution des formes grammaticales. In: MEILLET, Antoine. Linguistique historique et linguistique générale. Paris: Klincksieck, 1912. 
DOI: 10.12957/palimpsesto.2018.36608

Recebido em 8 de agosto de 2018.

Aceite em 19 de novembro de 2018. 